\title{
Tuning Primary Learning Style for Children with Secondary Behavioral Patterns
}

\author{
Maedeh Mosharraf \\ Technology-Enhanced Learning Laboratory, \\ University of Tehran, Iran
}

m.mosharraf@ut.ac.ir

\begin{abstract}
Personalization is one of the most expected features in the current educational systems. User modeling is supposed to be the first stage of this process, which may incorporate learning style as an important part of the model. Learning style, which is a non-stable characteristic in the case of children, differentiates students in learning preferences. This paper identifies a new hybrid method to initiate and update the information of children's learning style in an educational system. At the start-up phase, children's learning style information is gathered through the modified Murphy-Meisgeier Type Indicator for Children (MMTIC) questionnaire, which is based on the wellknown Myers-Briggs Type Indicator (MBTI). This primary information will be tuned by tracking children's behaviors during the learning process. Analytical data mining helped us to cluster these behaviors and find their patterns. The proposed method was applied on 81 fourth grade children in elementary school. Delivering results suggest that this method provides a good precision in recognizing children learning style and may be an appropriate solution for non-stability problems in their preferences.
\end{abstract}

Keywords: Automatic detection, children learning style, hybrid method, MBTI, personality type

\section{Introduction}

Rapid development of technology has made it a necessity to provide people life-long learning facilities. Life-long learning is the "life-long, voluntary, and self-motivated" pursuit of knowledge for either personal or professional reasons (Department of Education and Science, 2000). Although eLearning systems are identified as promoters of this term in the world of education, these systems do not consider children as one important category of users. In this regard much research has been done about cognitive traits, thinking and learning process, student modeling, and personalization in eLearning systems, but in most cases, college or high school students are considered (Gong, 2014; Romero \& Ventura, 2010; Truong, 2016). It seems that identification of chil-

Material published as part of this publication, either on-line or in print, is copyrighted by the Informing Science Institute. Permission to make digital or paper copy of part or all of these works for personal or classroom use is granted without fee provided that the copies are not made or distributed for profit or commercial advantage AND that copies 1) bear this notice in full and 2) give the full citation on the first page. It is permissible to abstract these works so long as credit is given. To copy in all other cases or to republish or to post on a server or to redistribute to lists requires specific permission and payment of a fee. Contact Publisher@InformingScience.org to request redistribution permission. dren's modeling methods is an obvious gap in the field of eLearning.

Learning style, defined as "a description of the attitudes and behaviors which determine an individual's preferred way of learning" (Honey \& Mumford, 1992, p. 1), is considered as an essential factor in the learning process and forms a part of the student model. Many educational theorists and researchers agree that in- 
corporating learning style in education has potential to make learning easier for students (Ghazali, Noor, \& Saad, 2015; Klašnja-Milićević, Vesin, Ivanović, \& Budimac, 2011). They believe that if student learning style is not supported by teaching environments, learners with strong preferences for a specific learning style might have difficulties in learning (Felder \& Silverman, 1988).

Psychologist's opinions about learning style are different and affected by several aspects. According to research conducted in 2004, 71 models of learning styles are identified and the major models based on theoretical importance and widespread uses are considered (Coffield, Moseley, Hall, \& Ecclestone, 2004). Kolb's learning style model, as the most widely used learning style model, has been used frequently in psychological and educational research (Kolb, 1984). The FelderSilverman learning style, as the second model, has a special place in engineering research (Felder \& Silverman, 1988). The Myers-Briggs Type Indicator (MBTI) is one of the most applicable learning style models, which investigates learners from the cognitive perspectives (Myers \& McCaulley, 1998). Since MBTI models personal characteristics of people context independently, and includes important aspects of learning, it has been used as one of the most popular learning style models.

Children's experiences of learning are too little to determine their learning style, so most of the learning style models are not applicable for them. Murphy-Meisgeier Type Indicator for Children (MMTIC) is a modified version of MBTI questionnaire introduced for children (Potts Gilbert, 1990). Unlike MBTI, there are few studies about MMTIC. One of the reasons of this issue could be related to frequent changes in children's personality, which leads to non-accurate information about their learning style after a short time. It seems that if learning management systems (LMSs) are equipped with techniques to update children's style automatically this problem could be solved.

In this paper we propose a new approach to modeling children's style statically based on a modified version of the MMTIC questionnaire. We automatically update children's profiles using behavioral logs of their interaction to eLearning system.

The paper is organized as follows. The next section starts with a brief overview on learning style modeling and introduces MBTI. The third section presents our proposed method to determine children's learning style in a LMS and tune their information automatically. Describing the provided child-specific LMS and presenting our experimental results are accomplished in the fourth section, and the final section concludes the paper and outlines future research.

\section{Background}

Personalized systems have many goals, which guide the methods of user modeling and adaptation as the two key processes of these systems. In this respect, numerous articles address the problem of student modeling in personalized learning systems (Gong, 2014). These studies can be classified according to contents of model, types of modeling process, representing model, and retrieving model (García, Amandi, Schiaffino, \& Campo, 2007). In a comprehensive study, Brusilovsky (2001) proposed several attributes to apply in user models of adaptive eLearning systems. Kim, Lee, and Ryu (2013) extended these attributes as shown in Figure 1. Learning style is a component of student preferences and MBTI is one of the most used models. 


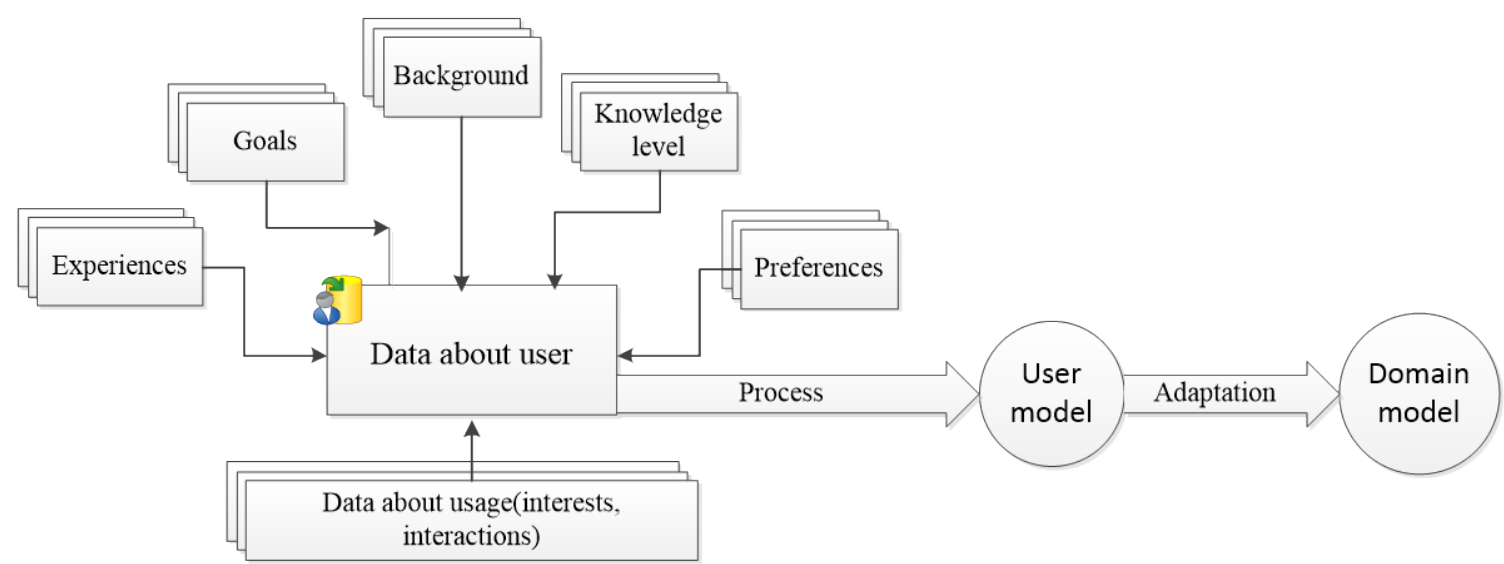

Figure 1. Elements of user model in an adaptive eLearning system, extended from (Brusilovsky, 2001; Kim et al., 2013)

\section{Learning Style Modeling}

Initiating and updating learning style information in a student model can be distinguished in two different ways (Brusilovsky, 1996): collaborative and automatic. In the collaborative approach, students provide explicit feedback, which can be used to initiate or update their information, while in the automatic one, the system uses learners' behaviors and actions. Applying a questionnaire is the easiest and common way for the first approach, whereas for the second several methods such as data mining algorithms are applied.

According to some theorists' opinions, learning styles are "flexibly stable" characteristics. In these approaches, learning styles of students are formed by their previous learning experiences and other environmental factors. Other researchers strongly relate learning styles to cognitive styles and abilities. They argue that learning styles remain stable over a long period of time. However, with respect to the life-long learning approach in eLearning systems, student learning styles are changed over time. In younger students, changes in their preferences occur with more frequency. In this respect, some researchers categorized all types of student modeling in two classes as statically or dynamically. The static student modeling refers to an approach where the student model is initialized only once. In contrast, the dynamic approaches frequently update the information of the student model (Graf, 2007).

Usually dynamic and automatic detection of learning style is based on system logs, so data mining methods play a key role in this work. For example, Özpolat and Akar (2009) use NBTree classification algorithm in conjunction with Binary Relevance classifier, which are applied on learning objects selected by students to recognize their learning style. In Chang, Kao, Chu, and Chiu (2009), a combined mechanism based on K-Nearest Neighbor classification and Genetic algorithm is proposed to classify students learning style. Dorça, Lima, Fernandes, and Lopes (2012) compare the Genetic Algorithm and Hidden Markov Model to determine and precisely adjust students' learning style automatically. They find the Markov based approach leads to more fine-tuned results than the Genetic Algorithm. Latham, Crockett, McLean, and Edmonds (2012) predict students' learning style through natural language dialogue. In this respect, they analyze the learning style models for language traits and conversational structure and adapt the generic logic rules to predict learning styles. Basheer, Ahmad, and Tang (2013) apply Multi-Agent System with the help of Ant Colony Optimization and Fuzzy Logic Search Algorithm as tools to detecting learning styles. 


\section{Myers-Briggs Learning Style}

In the early 1940s, Isabel Briggs Myers and her mother, Katherine Briggs developed MBTI as a test to be used for personnel selection. Myers believed that "different occupations favored different personality orientations, and that Jung's theory provided a theoretical link between personality and job performance" (Pittenger, 1993, p. 3). Consulting Psychologists Press acquired the right to sell the MBTI in 1975, and since then, the test has been successfully marketed to an extremely wide audience. Using mental habits, methods of understanding new information, and judging styles, the MBTI distinguishes a person's type according to four dichotomies, including (O'brien, Bernold, \& Akroyd, 1998):

- Most natural energy orientation and direction of focus: Extroversion (E)/ Introversion (I)

- Perceiving function and ways of taking in information: Sensing (S)/ Intuition (N)

- Decision making and ways of coming to conclusion: Thinking (T)/ Feeling (F)

- Orientation to outer life and attitude toward the external world: Judging (J)/ Perceiving (P)

Table 1. Characteristic of MBTI personality dimensions

\begin{tabular}{|c|c|c|c|}
\hline Dimension & \multicolumn{2}{|c|}{ Personality characteristics } & Dimension \\
\hline Extroversion & $\begin{array}{l}\text { Thinks out loud (by talking) } \\
\text { Being around people brings renewal } \\
\text { and energy } \\
\text { Is relaxed and confident } \\
\text { Dislikes complicated procedures and } \\
\text { gets impatient with slow jobs } \\
\text { Is enthusiastic about activities in- } \\
\text { volving action }\end{array}$ & $\begin{array}{l}\text { Thinks privately } \\
\text { Having time alone to think } \\
\text { replenishes his energy } \\
\text { Is intense, bottling up emo- } \\
\text { tions } \\
\text { Works on one thing for a long } \\
\text { time } \\
\text { Is hard to understand, quiet, } \\
\text { and shy; seems deep }\end{array}$ & Introversion \\
\hline Sensing & $\begin{array}{l}\text { Sees the trees in the forest } \\
\text { Handles details easily } \\
\text { Uses the five senses to perceive life } \\
\text { Learns best from an orderly se- } \\
\text { quence of details } \\
\text { Is aware of environment and chang- } \\
\text { es moods as physical surroundings } \\
\text { change }\end{array}$ & $\begin{array}{l}\text { Sees the forest (more global } \\
\text { thinker) } \\
\text { Sees possibilities and details } \\
\text { that others miss } \\
\text { Uses meaning and possibility } \\
\text { to perceive life } \\
\text { Likes to have and do things } \\
\text { differently from others } \\
\text { Is an initiator, promoter, and } \\
\text { inventor of ideas }\end{array}$ & Intuitive \\
\hline Thinking & $\begin{array}{l}\text { Looks at data to decide } \\
\text { Doesn't need harmony, but needs } \\
\text { fairness } \\
\text { Is more truthful than tactful, if } \\
\text { forced to choose } \\
\text { Is brief and businesslike } \\
\text { Finds ideas and things more interest- } \\
\text { ing than people } \\
\text { Holds firmly to a policy or convic- } \\
\text { tion }\end{array}$ & $\begin{array}{l}\text { Decides based on personal } \\
\text { feelings } \\
\text { Values harmony } \\
\text { Is more tactful than truthful, if } \\
\text { forced to choose } \\
\text { Finds it difficult to be brief } \\
\text { and businesslike } \\
\text { Is more interested in people } \\
\text { than things or ideas } \\
\text { Arouses enthusiasm }\end{array}$ & Feeling \\
\hline
\end{tabular}




\begin{tabular}{|c|c|c|c|}
\hline Judging & $\begin{array}{l}\text { Works first, then feels a freedom to } \\
\text { play } \\
\text { Prefers predictability in schedule } \\
\text { Likes things to be decided } \\
\text { Is structured } \\
\text { Has settled opinions }\end{array}$ & $\begin{array}{l}\text { Plays first, then works } \\
\text { Likes dealing with events as } \\
\text { they come } \\
\text { Likes things to remain open } \\
\text { Is flexible } \\
\text { Has trouble making decisions }\end{array}$ & Perceiving \\
\hline
\end{tabular}

All possible combinations of these dichotomies can occur, which result in a total number of 16 types. Table 1 describes a brief explanation of the characteristics and preferences that MBTI has identified (Behaz \& Djoudi, 2012; Brightman, 2007; O’brien, et al., 1998).

Despite the numerous studies which have been done on MBTI in learning and training process, investigating MBTI as learning style in eLearning systems starts from 2000 (Dewar \& Whittington, 2000). Afterwards, some research shows students with different learning styles behave dissimilarly in learning environments and with respect to learning objects (Kim et al., 2013).

The MBTI indicates not only the learners' preferences, but also clearly expresses the preferences for particular poles over their opposite. For example, Figure 2 is a summarization of typical report from Consulting Psychologists Press, the MBTI authority organization (Choi, Deek, \& Im, 2008). In this example, $\mathrm{E}$ is showing a greater presence on a moderate level, over its counterpart, I. Similarly, in other dimensions dominant preferences are shown.

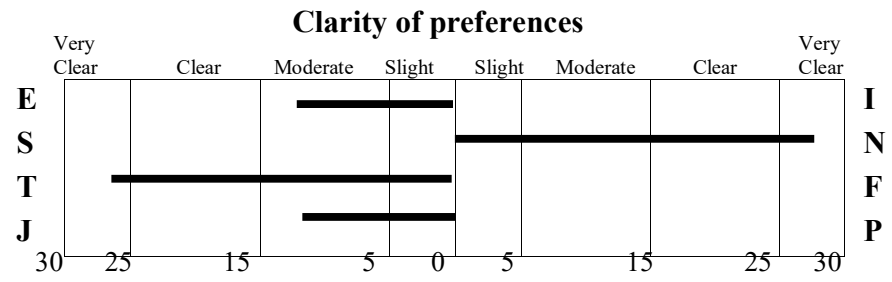

Figure 2. The strengths of MBTI type preferences

Although several versions of MBTI questionnaire are designed, they are all validated for people who are over 18 years old (Myers \& McCaulley, 1998). The MMTIC is a self-report instrument designed for personality and psychological type assessment in youth aged 7-18 (Center for Application of Psychological Type, 2012). Children's lack of experience in learning activities and their learning styles non-stability have caused this questionnaire be mostly applied in learning activities instead of other domains. The dynamics of the MMTIC dimensions refer to how these four preferences interact in each individual. Like the MBTI, this questionnaire measures personality preferences on the same four sets. Both the MBTI and the MMTIC are multiple choice tests.

\section{Incorporating Learning Style into a Child-Specific LMS}

The aim of this study is investigating how learning styles can be incorporated in LMSs. Answering a psychological questionnaire is a common way for statically determining learning style. Although this method is easy and usual in learning environments, the static nature of the questionnaire makes it fault prone. Combining this static method with a dynamically driven one is the approach of this paper, which is applied to elementary school students. Receiving student's logs and pattern of their behavior, the system updates student profile information frequently.

The questionnaire describes the learning style of students at a specific point in time. Furthermore, some other problems such as misunderstanding of self-type can make the questionnaire results 
not reliable. In general, the questionnaire has to deal with the problem that the given answers might not correspond to the real behaviors that the questions aim to investigate.

Therefore, using a questionnaire as an instrument for identifying learning styles is based on several assumptions. The first assumption is that students are motivated to fill out the questionnaire properly and to the best of their knowledge about their preferences. Secondly, filling out a questionnaire about the preferences requires that the students are aware of their preferred way of learning. Besides, children's learning styles have not yet stabilized and may change gradually (Warner, 2000). As soon as learning style changes, the results of the questionnaire are not valid anymore and a student would have to do it again. This approach would raise new issues, dealing with how to identify an occurring change in learning style and how to motivate students to fill out the questionnaire several times.

This problem can be solved through updating information of students' learning style based on their behavior and learning preferences. Table 2 is a summary of research conducted on learning preferences in MBTI dimensions (Dewar \& Whittington, 2000; Lawrence, 1993). According to this table, some behaviors of students with different learning style are various. We use all the features mentioned in this table to extract students' learning preferences in online environments.

Table 2. Learning preferences associated with dimensions of MBTI

\begin{tabular}{|c|c|c|c|}
\hline Dimension & \multicolumn{2}{|c|}{ Learning preferences } & Dimension \\
\hline Extroversion & $\begin{array}{l}\text { Prefers action } \\
\text { Plunges into new experiences } \\
\text { Has a relatively short attention span } \\
\text { Eagerly attends to interruptions } \\
\text { Likes to work by trial and error } \\
\text { Wants to experience things so as to } \\
\text { understand them }\end{array}$ & $\begin{array}{l}\text { Considers/thinks before acting } \\
\text { Holds back from new experienc- } \\
\text { es } \\
\text { Spends time in thought, before } \\
\text { and after actions } \\
\text { Dislikes interruptions } \\
\text { Prefers setting his/her own stand- } \\
\text { ards when possible } \\
\text { Asks questions to allow under- } \\
\text { standing something before }\end{array}$ & Introversion \\
\hline Sensing & $\begin{array}{l}\text { Prefers facts and concrete information } \\
\text { Is realistic and practical } \\
\text { Going step by step } \\
\text { Prefers memorizing to finding reasons } \\
\text { Likes to know the "right way" to } \\
\text { solve problems } \\
\text { Enjoys using skills already learned } \\
\text { more than learning new ones }\end{array}$ & $\begin{array}{l}\text { Prefers abstract or theoretical } \\
\text { information } \\
\text { Is imaginative and loves ideas } \\
\text { and possibilities } \\
\text { Jumps to conclusions; makes } \\
\text { factual errors } \\
\text { Has intellectual interests } \\
\text { Likes problems that require new } \\
\text { ways of being solved } \\
\text { Seems to like something new all } \\
\text { the time }\end{array}$ & Intuitive \\
\hline Thinking & $\begin{array}{l}\text { Contributes intellectual criticism } \\
\text { Wants logical reasons before accept- } \\
\text { ing new ideas } \\
\text { Is objective }\end{array}$ & $\begin{array}{l}\text { Is motivated by others } \\
\text { Permits feelings to override logic } \\
\text { Is subjective }\end{array}$ & Feeling \\
\hline Judging & $\begin{array}{l}\text { Is more decisive than curious } \\
\text { Likes assignments to be clear and } \\
\text { definite } \\
\text { Tries to make situations conform to } \\
\text { his or her own standards, "the way } \\
\text { they ought to be" } \\
\text { Aims to be right }\end{array}$ & $\begin{array}{l}\text { Is more curious than decisive } \\
\text { Is flexible, adaptable and tolerant } \\
\text { Looks for new experiences, ex- } \\
\text { pects to be interested } \\
\text { Aims to miss nothing }\end{array}$ & Perceiving \\
\hline
\end{tabular}


We expect that the students' preferences in online learning environments to be same as the offline ones. So, we track behaviors of students in learning management systems and update their information models based on the extracted patterns that relate to learning style dimensions. But, for solving the cold start problem at the start-up phase of the system - not knowing the learner's profile - we use a personality indicator questionnaire. Figure 3 illustrates the process of our proposed method.

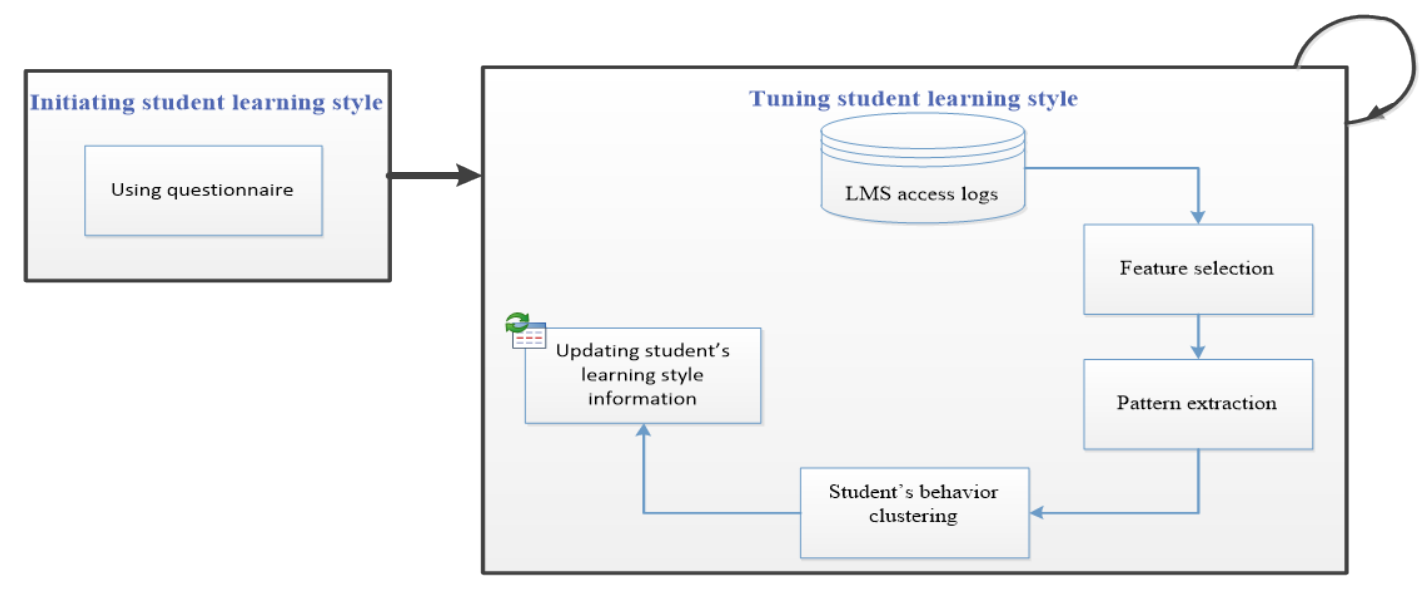

Figure 3. The process of tuning primary learning style with learner access logs

\section{A. Initiating Student Learning Style: Static Determination}

To identify the learning style of children at the starting-up of the system, we use the child personality indicator questionnaire. This questionnaire is a modified version of MMTIC that is translated to Persian language and localized based on some linguistic and cultural aspects. This test, which contains 70 questions about children preferences, is approved by a panel of psychology and pedagogy experts as discussed in a previous paper (Mosharraf, Taghiyareh, \& Kharrat, 2013). The children personality indicator questionnaire is a self-reporting instrument in which a child is asked to choose between two preferences, neither of which is wrong. Same as MBTI and MMTIC, the four measured preferences in this test are E/I, S/N, T/F, and J/P. Test scores can range from one extreme to a contrasting extreme and each pole of the dimensions has different characteristics. Children scores can be any number in the spectrum of two poles.

\section{B. Tuning Student Learning Style: Automatic Determination}

As soon as a child's learning style changes, the results of the questionnaire may not be valid. To tune information of children's learning style, we use the new automatic method, which is based on tracking children's behaviors. In our proposed method, no additional effort is needed on the students' side in order to enable the system to get information about their learning styles. In this regard, students interact with the LMS only for learning activities, but the system monitors their behavior simultaneously. At arbitrary times, LMS administrators can check system access logs. If students' behaviors are recognized as contrary to the determined learning style stored in their model, information of student model should be revised. For this purpose, some data mining techniques are applied to students' access logs to extract behavioral patterns of each student.

In online environments, learning behaviors regarding the patterns are clustered based on selected features extracted from Graf (2007). Considering children limitations in the LMSs, these features include:

- Learning contents

- Outlines

- Examples 
- Assessments

- Exercises

Regarding different features, the number of visits and the duration students spend on these objects are used as their behavioral patterns. Learning preferences, which are mentioned in Table 2, corroborate this claim. Occurrence frequency of learning patterns that is used in any learning style dimensions is context sensitive and affected by course subject. Therefore, we use the behavior of students to determine thresholds of each pattern. For this purpose, we cluster all the children's behaviors in three categories: low, middle, and high.

The category of learning patterns which is labeled "high" is matched to one style dimension. For example, sensing learners favor concrete materials like facts and data, so they prefer to learn from examples. Therefore, a high number of visited examples and time spent on them may be indicants of sensing style. On the other hand, intuitive learners prefer to learn from abstract materials such as theories and their underlying meaning, so they probably choose to learn from content objects. A high number of visited contents and time spending on them can be demonstrators of initiative style. Furthermore, sensing learners like to solve problems in accordance with a standard procedure, which can be indicated by a high interest in examples. In these students, multiple reviews in examples are done to see and learn existing approaches and a high number of assessments and exercises are conducted in order to check the acquired knowledge. Regarding Table 1 and Table 2 , sensing learners are more patient with details and work carefully, but slowly. With respect to the preference for working slowly, the times taken for visiting examples, assessments, and exercises are considered as a pattern. However, intuitive learners tend to be more creative. Therefore, they are expected to be better in answering questions about developing new solutions, which requires the understanding of underlying theories and concepts. In contrast to sensing students, intuitive learners like challenges.

Research shows gender differences in feeling/ thinking dimension of MBTI and this issue has caused students' behaviors to become unpredictable in different contexts (Dewar \& Whittington, 2000). In addition, both perceiving and judging types indicate an appreciation for online learning environments, but extracted patterns of them are not valid for children. According to O'brien et al., (1998) sensing/ intuitive dimension is proposed as the dimension with most differences in learning behaviors. Because of the importance of group learning, the introvert/ extravert dimension is also important. Therefore, we study only two dimensions in this paper: E/I and S/N. Kim et al. (2013) verified that $\mathrm{E} / \mathrm{I}$ and $\mathrm{S} / \mathrm{N}$ dimensions are the most dominant functions of the MBTI in learning behaviors. Table 3 summarizes all the selected features that are available in children learning behaviors.

Table 3. Selected features of learning behaviors related to learning style dimensions

\begin{tabular}{|l|l|l|l|l|}
\hline Features & Pattern & Pattern Description & E/I & S/N \\
\hline \multirow{3}{*}{ Outline } & OutlineVisit & Number of visited outlines & $\mathrm{U}$ & $\mathrm{N}$ \\
\cline { 2 - 5 } & OutlineStay & Percentage of time spent on outlines & $\mathrm{I}$ & $\mathrm{N}$ \\
\hline \multirow{3}{*}{ Content } & ContentVisit & Number of visited content objects & $\mathrm{I}$ & $\mathrm{N}$ \\
\cline { 2 - 5 } & ContentStay & Percentage of time spent on content objects & $\mathrm{I}$ & $\mathrm{N}$ \\
\hline \multirow{3}{*}{ Assessment } & ExampleVisit & Number of visited examples & $\mathrm{U}$ & $\mathrm{S}$ \\
\cline { 2 - 5 } & ExampleStay & Percentage of time spent on examples & $\mathrm{I}$ & $\mathrm{S}$ \\
\cline { 2 - 5 } & AssessmentVisit & Number of performed self-assessment questions & $\mathrm{E}$ & $\mathrm{S}$ \\
\cline { 2 - 5 } & AssessmentStay & Percentage of time spent on self-assessment tests & $\mathrm{I}$ & $\mathrm{S}$ \\
\cline { 2 - 5 } & AssessmentRetry & Number of retry for assessment & $\mathrm{E}$ & $\mathrm{S}$ \\
\hline \multirow{3}{*}{ Exercise } & ExerciseVisit & Number of performed exercises & $\mathrm{E}$ & $\mathrm{S}$ \\
\cline { 2 - 5 } & ExerciseStay & Percentage of time spent on exercises & $\mathrm{E}$ & $\mathrm{U}$ \\
\hline
\end{tabular}

In the above table: "U" is the acronym of "Undefined". 
In addition to the number of visits and duration students spend on learning objects, the pattern of navigation for each learning style dimension is different (Anohina, Vilkelis, \& Lukasenko, 2009; Graf, 2007). For example, thinking students like to analyze and solve the practical exercises using course knowledge. So, the navigation plan of these students is usually the sequence of contents, examples, and then exercises. On the other hand, feeling students use practical exercises to be familiar with course subject; therefore, their navigation plan is exercises, examples, and contents (Bachari, Abdelwahed, \& Adnani, 2010). Table 4 indicates the patterns of navigation in the E/I and $\mathrm{S} / \mathrm{N}$ dimensions of learning style. All the patterns of student navigation, which are the sequential subset of any presented navigation in this table, can be applied to determine learning style.

Table 4. Navigation pattern related to learning style dimensions

\begin{tabular}{|l|l|}
\hline Learning style dimension & Navigation pattern \\
\hline $\mathrm{I}$ & Learning contents, Assessments, Exercise \\
\hline $\mathrm{E}$ & Assessment, Exercise, Learning content, Example \\
\hline $\mathrm{S}$ & Example, Learning content, Assessment, Exercise \\
\hline $\mathrm{N}$ & Exercise, Learning content, Example \\
\hline
\end{tabular}

Although each dimension of learning style has specified patterns, some of them may yield conflicting results. As Table 3 shows, one relevant pattern of IN students is OutlineStay, but for IS students this object can be a contradiction. For solving this problem, we use students' scores in each dimension of learning style that are obtained by the questionnaire. Like frequency of learning behaviors, we divide the scores of each learning style dimension in three groups as weak, moderate, and strong (presented in Table 5). A weak style is considered as undefined. Considering dominant style, if the indicants of weak style in one dimension and strong style in the other are gathered in a child, we expect the strong style to dominate. In other cases, learning style is undefined. When conflict occurs in some features and learning style becomes undefined, the system uses other learning features to resolve this conflict. In the mentioned instance, OutlineVisit or ExampleVisit can be determiner of learning style.

Table 5. Segmentation of learning style scores

\begin{tabular}{|l|l|}
\hline Score range & Learning style \\
\hline $0-30$ & Weak \\
\hline $30-70$ & Moderate \\
\hline $70-100$ & Strong \\
\hline
\end{tabular}

\section{Experimental Results}

One of the main difficulties of research about children is encouraging them to effectively participate in all the research stages. In addition, children's education should be done in special environments. For example:

- Children's motivation for engaging in learning activities (Gagne \& Deci, 2005);

- Effect of operative feedback and interactive learning environment (Mosharraf \& Taghiyareh, 2012);

- Limited children's working memory and profitable user interface for system (Wang, Li, \& Shi, 2007);

- Children's curiosity and fantasy-driven nature (Asgari \& Kaufman, 2004).

Providing some arrangements to obtain these conditions was one of the first steps in this research. To this end, we implemented a learning management system for children (Mosharraf, Taghiyareh, \& Nasirifard, 2013). The Child-specific LMS provides all the proposed features which are identi- 
fied in Table 3. In order to investigate learners' behaviors, the learning materials are distinguished according to the proposed features. In addition, for some features, an additional description of the material is specified. For example, with the aim of distinguishing between contents and outlines, we extend our implemented LMS by including the possibility of using meta-data for teachers and course developers to specify information about the created learning materials.

\section{A. Extensions Regarding Questionnaire Results}

The proposed approach for defining children's learning style was examined on fourth-grade elementary school children. For this purpose, 81 students were asked to respond to the prepared questionnaire. This process was done when a student logged in to the system for the first time. Table 6 shows the results of children styles obtained by the questionnaire.

Table 6. Questionnaire result of learning style

\begin{tabular}{|l|l|l|l|l|}
\hline Learning style dimension & Min & Max & Median & Std Deviation \\
\hline E/I & 22.2 & 88.9 & 44.4 & 17.1 \\
\hline J/P & -27.8 & 22 & 11 & 14.7 \\
\hline S/N & -77 & 66.7 & -11 & 36.8 \\
\hline T/F & -25 & 25 & 0 & 19.9 \\
\hline
\end{tabular}

We normalize all the children's scores in each dimension of learning preferences to $(-100,100)$ as $\mathrm{E} / \mathrm{I}, \mathrm{J} / \mathrm{P}, \mathrm{S} / \mathrm{N}$, and T/F. As Table 6 shows, all the examined children are extravert. This issue can be relevant to children's conditions at an early age and their tendency to be in a group of friends. The achieved scores for $\mathrm{J} / \mathrm{P}$ and $\mathrm{T} / \mathrm{F}$ dimensions are less than 30 for all of the students, which lead to weak preferences in these dimensions. One reason for this may be relevant to inappropriate perception of children from these dimensions of their personality. The recorded scores in the $\mathrm{S} / \mathrm{N}$ dimension show high diversity of the examined children. Children's distribution is seen in all the three strong, moderate, and weak groups in intuition preferences. But, the sensing children are located in moderate and weak groups.

\section{B. Extensions Regarding Behavioral Tracking}

Tracking children behaviors in learning environments can help the system to respond to children's preferences when they change and always deliver personalized services to them. Students' access logs in LMS make it possible. The LMS logs of children's interactions in biology context and creatures' course was used for our research. Collected data set contain 169,908 records related to 23 days of student training.

The time-consuming step in detection of children's style was data cleaning and outlier removing. Using obtained data, we calculated the number of visited learning objects and the time spent on them for each child. After that, we applied K-Means algorithm on each of the learning features, which are mentioned in Table 3, separately and divided the children in three groups based on their behaviors. So, we used the information of this table to determine the expected style for all of the behaviors that are labeled "high".

In order to determine learning style of children based on their navigation pattern, we used ApprioriAll algorithm (Agrawal \& Srikant, 1995). This algorithm is applied on all the features of Table 4. But, the low support and confidence in the extracted sequences make these features to be not valid.

To evaluate the effectiveness of our hybrid method to detect the children's style, we compare the result of the proposed automatic method with questionnaire as a common approach in learning style modeling. We expect the results of both methods to be same after short time duration. Au- 
tomatic detection of children's style was done 17 and 23 days after answering the questionnaire. Since these time durations are short, it is expected that the children's styles are not changed significantly. Therefore, calculating the precision of our method needs to use some measures. We define the precision of automatic method as:

$$
\text { Precision }=\frac{\sum_{i=1}^{n} \operatorname{Sim}\left(L S_{\text {automatic }}, L S_{\text {questionnaire }}\right)_{i}}{\mathrm{n}} .100,
$$

Where LS ${ }_{\text {automatic }}$ refers to the learning styles diagnosed by our automatic method. Also, LS questionnaire represents the learning styles indicated by the prepared questionnaire, and $\mathrm{n}$ is the number of all the students. The function Sim compares its two parameters LS automatic $_{\text {and }}$ LS questionnaire and returns 1 if both are equal. Table 7 shows the precision of the implemented system in automatic detection of children's style.

Table 7. System precision

\begin{tabular}{|l|l|l|}
\hline Time duration & Extravert / Introvert (E/I) & Sensing / Intuitive (S/N) \\
\hline 17 days & $56.79 \%$ & $72.84 \%$ \\
\hline 23 days & $69.14 \%$ & $80.24 \%$ \\
\hline
\end{tabular}

The important restriction in our system evaluation is the low time interval between the static and automatic tests. Since the style of children can change repeatedly, the time interval between the two tests should be low. However, this short interval leads to few students' access logs which may be not enough for extracting their patterns. We hope that as time passes and more children's data is collected this will lead to detecting better patterns of their behaviors; the results of the system tend to the reality.

The proposed automatic detection of children's style is focused on only two dimensions of their learning style. According to the mentioned results in Table 7, this method has shown an acceptable similarity in the $\mathrm{S} / \mathrm{N}$ dimension. Considering the problem of a questionnaire as a static method for determining children's learning style, our results in automatic method can be acceptable even in the E/I dimension. Due to our achievements, diagnosing the E/I dimension of learning style based on children's behavioral patterns in an online learning environment needs more access logs. However, we need to focus on learners' behaviors on the other dimensions and not rely only on the questionnaire results. It seems this method can accelerate learners' modeling process, which is a time-consuming procedure in adaptive learning processes.

In the automatic method, we assign all the learning preferences of children in the E/I and S/N dimensions to learning objects and find their appropriate behaviors. Accomplishing these assignments in the T/F and $\mathrm{J} / \mathrm{P}$ dimensions needs more research on the children's preferences and learning behaviors. As shown in our study, perception of children in these dimensions is weak. So, investigating this issue can face many troubles.

\section{Conclusion}

In this paper we concentrated on learning styles of children considering the life-long learning approach. Since the learning experiences in children are too little to gain the accurate perception of their style, we used personality type instead. For initiating primary information of children's learning style, a modified version of the MMTIC questionnaire was used. The questionnaire results showed almost all of the children are extravert, but in absorbing information they can be sensing or intuitive. Also, it seems that children do not have any strong preferences in the perceiving/ judging and thinking/ feeling dimensions.

For solving the non-stability problem of children's learning style, we used access logs of the system in order to tune the children's model. In this regard, we applied clustering algorithm on ex- 
tracted behavioral patterns of children. Regarding learning preferences which are compatible to each cluster, children's information can be tuned. Experimental results show this method has an acceptable precision in diagnosing children's learning style.

Although tuning the student models is done based on automatic approach, it does not work fully automatically. Pre-processing steps including data cleaning and outlier removing are case sensitive. In addition, some analyses are context based and need human opinions. Due to these restrictions, it would be very useful to improve eLearning systems with automatic data mining methods. In addition, the experimental results show children's navigation plan cannot be applicable in the case of learning style detection. However, this feature may be used in other age classes. Furthermore, there are two aspects of MBTI, perceiving/ judging and thinking/ feeling, which our results did not find good criteria for categorizing children at this age, but we believe they may be more effective in older students. All the findings and prototypes developed in this paper can be used as the basis for further research and developments regarding providing advanced adaptivity in LMSs.

\section{References}

Agrawal, R., \& Srikant, R. (1995). Mining sequential patterns. Proceedings of the Eleventh International Conference on Data Engineering. Taipei.

Anohina, A., Vilkelis, M., \& Lukasenko, R. (2009). Incremental improvement of the evaluation algorithm in the concept map based knowledge assessment system. International Journal of Computers, Communications \& Control, 5, 6-16.

Asgari, M. \& Kaufman, D. (2004). Relationships among computer games, fantasy, and learning. Vancouver.

Bachari, E. E., Abdelwahed, E. H., \& Adnani, M. E. (2010). Design of an adaptive eLearning model based on learners personality. Ubiquitous Computing and Communication Journal, 5, 1-8.

Basheer, G. S., Ahmad, M. S., \& Tang, A. Y. C. (2013). A conceptual multi-agent framework using ant colony optimization and fuzzy algorithms for learning style detection. Kuala Lumpur, Malaysia.

Behaz, A. \& Djoudi, M. (2012). Adaptation of learning resources based on the MBTI theory of psychological types. IJCSI International Journal of Computer Science Issues, 19, 135-141.

Brightman, H. (2007). GSU Master Teacher Program: On learning styles. Accessed 8 April 2012 from http://www2.gsu.edu/ dschjb/wwwmbti.html

Brusilovsky, P. (1996). Methods and techniques of adaptive hypermedia. User Modeling and User-Adapted Interaction, 2, 87-129.

Brusilovsky, P. (2001). Adaptive hypermedia. User Modeling and User-Adapted Interaction, 11, 87-110.

Center for Application of Psychological Type. (2012). MMTIC: Essential materials. Accessed 5 August 2013 from http://www.capt.org/catalog/Personality-Assessment-Children.htm

Chang, Y.-C., Kao, W.-Y., Chu, C.-P., \& Chiu, C.-H. (2009). A learning style classification mechanism for e-learning. Computers \& Education, 53, 273-285.

Choi, K. S., Deek, F. P., \& Im, I. (2008). Exploring the underlying aspects of pair programming: The impact of personality. Information and Software Technology, 50, 1114-1126.

Coffield, F., Moseley, D., Hall, E., \& Ecclestone, K. (2004). Should we be using learning styles? What research has to say to practice. London: Learning and Skills Research Centre, University of Newcastle upon Tyne.

Department of Education and Science. (2000). Learning for life: White paper on adult education, Dublin: Stationery Office. 
Dewar, T. \& Whittington, D. (2000). Online learners and their learning strategies. Journal of Educational Computing Research, 23, 415-433.

Dorça, F. A., Lima, L. V., Fernandes, M. A., \& Lopes, C. R. (2012). Automatic student modeling in adaptive educational systems through probabilistic learning style combinations: A qualitative comparison between two innovative stochastic approaches. Journal of the Brazilian Computer Society, $19,43-58$.

Felder, R. M., \& Silverman, L. K. (1988). Learning and teaching styles in engineering education. Engineering Education, 78, 674-681.

Gagne, M., \& Deci, L. E. (2005). Self-determination theory and work motivation. Journal of Organizational Behavior, 26, 331-362.

García, P., Amandi, A., Schiaffino, S., \& Campo, M. (2007). Evaluating Bayesian networks precision for detecting students learning styles. Computers \& Education, 49, 794-808.

Ghazali, A. S. M., Noor, S. F. M, Saad, S. (2015). Review of personalized learning approaches and methods in e-learning environment. International Conference on Electrical Engineering and Informatics (ICEEI), Denpasar.

Graf, S. (2007). Adaptivity in learning management systems focussing on learning styles. Austria: Unpublished doctoral dissertation, Vienna University of Technology.

Gong, Y. (2014). Student modeling in intelligent tutoring systems. PhD dissertation, University of British Columbia.

Honey, P., \& Mumford, A. (1992). The manual of learning styles (3rd ed.). Maidenhead: Peter Honey.

Kim, J., Lee, A., \& Ryu, H. (2013). Personality and its effects on learning performance: Design guidelines for an adaptive e-learning system based on a user model. International Journal of Industrial Ergonomics, pp. 450-461.

Klašnja-Milićević, A., Vesin, B., Ivanović, M., \& Budimac, Z. (2010). E-Learning personalization based on hybrid recommendation strategy and learning style identification. Computers \& Education, 56, 885899.

Kolb, D. A. (1984). Experiential learning: Experience as the source of learning and development (Vol. 1). Englewood Cliffs, NJ: Prentice-Hall.

Latham, A., Crockett, K., McLean, D., \& Edmonds, B. (2012). A conversational intelligent tutoring system to automatically predict learning styles. Computers \& Education, 59, 95-109.

Lawrence, G. (1993). People types \& tiger stripes (3rd ed.). New York: Center for Applications of Psychological Type.

Mosharraf, M., \& Taghiyareh, F. (2012). Improving student success rates through a semi-personalized feedback system. Groningen, s.n.

Mosharraf, M., Taghiyareh, F. \& Kharrat, M. (2013). Equipping children elearning systems with a hybrid personality type indicator. Shiraz, s.n.

Mosharraf, M., Taghiyareh, F. \& Nasirifard, P. (2013). Developing a child-centred LMS to enhance learning and creativity of students in elementary school. Bulletin of the IEEE Technical Committee on Learning Technology, 15, 10-13.

Myers, I. \& McCaulley, M. (1998). Manual: A guide to the development and use of the Myers-Briggs Type Indicator. Palo Alto: Consulting Psychologists Press.

O'brien, T., Bernold, L., \& Akroyd, D. (1998). Myers-Briggs type indicator and academic achievement in engineering education. International Journal of Engineering Education, 14, 311-315.

Özpolat, E., \& Akar, G. (2009). Automatic detection of learning styles for an e-learning system. Computers \& Education, 53, 355-367. 
Pittenger, D. J. (1993). Measuring the MBTI...and coming up short. Journal of Career Planning and Employment, 54, 48-53.

Potts Gilbert, A. (1990). Master thesis: A comparison of the Murphy-Meisgeier Type Indicator for Children and the Myers-Brigs Type Indicator. Ohio: Graduate School of the Ohio State University.

Romero, C., \& Ventura, S. (2010). Educational data mining: A review of the state of the art. EEE Transaction on Systems, Man, and Cybernetics -Part C: Applications and Reviews, 40, 601-618.

Truong, H. M. (2016). Integrating learning styles and adaptive e-learning systems: Current developments, problems and opportunities. Computers in Human Behavior, 55, 1185-1193.

Wang, T., Li, X., \& Shi, J. (2007). An avatar-based approach to 3D user interface design for children. Charlotte, s.n.

Warner, S. (2000). The effects on student's personality preferences from participation in Odyssey Of The Mind. Morgantown, West Virginia: PH.D thesis: College of Human Resources and Education at West Virginia University.

\section{Biography}

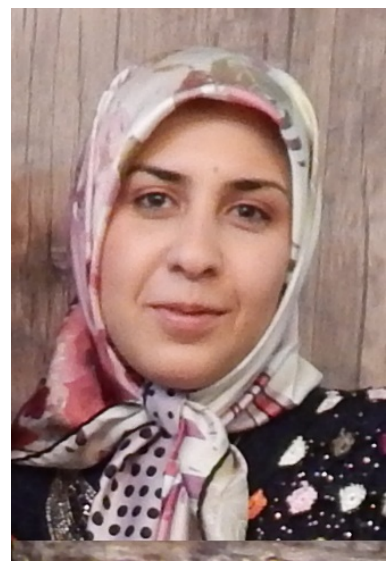

Maedeh Mosharraf is a Ph.D. candidate at the Technology-Enhanced Learning Laboratory at University of Tehran. She received her B. Sc. and M. Sc. in Information Technology engineering from University of Tehran in 2010 and 2013, respectively. During these years, she has been involved in a variety of research works like new Information Technology Applications, Web-Based Educational Systems, Technology-Enhanced Learning, and Psychological Theories, as well as open educational resources combined with semantic web technology, which has been covered in her Ph.D. thesis. 